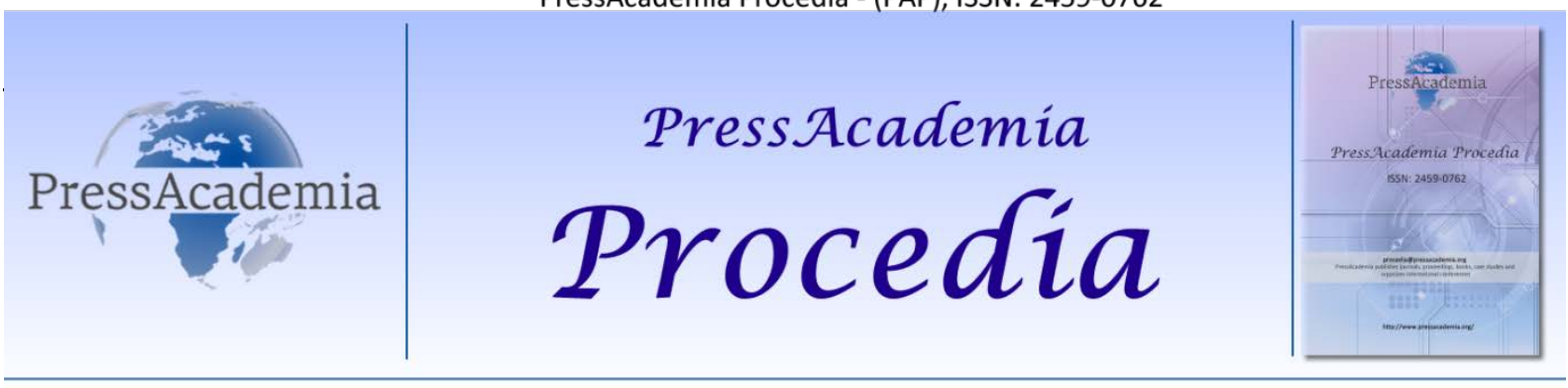

Global Business Research Congress (GBRC), May 26-27, 2016, Istanbul, Turkey.

\title{
PRICING: A LITERATURE REVIEW
}

\section{DOI: 10.17261/Pressacademia.2016118634}

Cahid Ozdeveci ${ }^{1}$, Mustafa Halid Karaarslan ${ }^{2}$

${ }^{1}$ Karabük Üniversitesi. cahidozdeveci@karabuk.edu.tr

${ }^{2}$ Karabük Üniversitesi. mustafahk@karabuk.edu.tr

\begin{abstract}
Pricing is one of the marketing mix elements which least researched topic in the marketing literature. Pricing decisions have a huge impact on business success. Pricing has important role to execute business aims. The most difficult side of pricing is that how to harmonize business aim with pricing decisions. Thanks to this study, it is done a literature review about pricing which gradually become more important. By doing literature review it is analyzed researches about pricing in the literature and it is made a suggestion for future research. It is thought that this study contributes both executives in the institutions and academicians are interested in pricing topic.
\end{abstract}

Keywords: Pricing, price, marketing

JEL Codes: L11, L16

\section{FIYATLANDIRMA: BIR LITERATÜR TARAMASI}

\section{ÖZET}

Fiyatlandırma kavramı pazarlama literatüründe en az araştırma yapılan pazarlama karması unsurudur. Fiyatlandırma kararlarının işletme başarısı üzerindeki etkisi büyüktür. İşletme amaçlarını gerçekleştirmede fiyatlandırmanın rolü önemlidir. Fiyatlandırmanın en zor kısmı firmanın amaçlarıyla fiyatlandırma kararlarının nasıl uyumlu hale getirileceğidir. Bu çalışma sayesinde gün geçtikçe önemi daha da artan fiyatlandırma hakkında literatür taraması yapılmıştır. Yapılan literatür taraması ile fiyatlandırma konusunda literatürde bulunan çalışmalar analiz edilmiş ve bundan sonra yapılacak çalışmalar için önerilerde bulunulmuştur. Bu çalışmanın hem kurumlardaki yöneticilere hem de fiyatlandırma konusuyla ilgilenen akademisyenlere katkı sağlayacağı düşünülmektedir.

Anahtar Kelimeler: Fiyatlandırma, fiyat, pazarlama,

JEL Kodları: L11, L16

\section{GiRiş}

Fiyat bir ürün veya hizmet için ödenen para miktarıdır (Karunakaran, 2008: 160). Her kullanılan ürün veya hizmetin, bir başka deyişle, her faydanın bir fiyatı bulunmakta fakat bunlar farklı tarzlarda ifade edilebilmektedir. Örneğin; ev sahibine ödenen bedel olan kira; bankadan borç alınan paraya ödenen faiz; aracı kişiye ödenen komisyon fiyatın değişik şekillerde ifade ediliş biçimleridir (Oluç, 2006: 205).

Pazarlama karmasında diğer tüm kalemler maliyet unsuruyken, fiyat gelir sağlayan tek kalemdir (Kotler ve Armstrong, 2012: 290). Fiyat bir işletmenin kârını etkileyen en önemli belirleyicidir ve aynı zamanda pazarlama karmasının en esnek elemanıdır (Karunakaran, 2008: 160). 
Fiyat, yeri geldiğinde, ciddi sonuçları olması itibariyle dikkatle kullanılması gereken etkili bir pazarlama aracıdır (Hundekar vd., 2010: 78). Fiyat, kısa dönemde ürüne olan ilgiyi artırabilmek için de bir tutundurma aracı olarak kullanılabilmektedir (Peterson, 2007: 188). Fiyatlandırma kararları ve fiyat rekabeti pazarlamacıların yüzleştiği problemlerin başında gelmekte ve her bir şirket için kritik bir karar noktası olarak durmaktadır (Karunakaran, 2008: 160).

Bu çalışmada pazarlama konusundaki fiyatlandırma çalışmaları incelenmiş olup, ekonomide ve bankacııık alanında yapılmış olan çalışmalar konu kapsamına dahil edilmemiştir.

\section{FIYATLANDIRMA STRATEJILERI}

Fiyatlandırma stratejileri maliyete, talebe, rekabete göre fiyatlandırma ve değer temelli fiyatlandırma şeklinde dörde ayrılmaktadır.

\subsection{Maliyete Göre Fiyatlandırma}

Maliyete dayalı fiyatlandırma üretim, dağııım ve satış için gösterilen çabayı ve girilen riski karşılayabilmek adına ürünün maliyetine belirli bir oran eklenerek yapılmaktadır (Kotler ve Armstrong, 2012: 295). Maliyet temelli yaklaşım basit, maliyetin geri dönüşünün garanti olması ve değişen koşullara uyum göstermesi bakımından avantajlı yanlara sahiptir (Sherlekar, Prasad ve Victor, 2010: 200). Buna karşın maliyet temelli fiyatlandırmada müşterinin fiyatlandırmaya ilişkin tercihleri göz ardı edilmesinden dolayı dezavantajı olduğu söylenebilir (Phillips, 2011: 45).

\subsection{Talebe Göre Fiyatlandırma}

Ekonomide talep kavramı çoğu zaman belirli bir ürün ve hizmete duyulan gereksinim veya arzu gibi düşünülse de kastedilen anlam itibariyle, talep, bir bedel karşılığında bir ürün veya hizmete olan isteğin veya arzunun satın alma gücüyle desteklenmesini ifade etmektedir. Bir başka ifadeyle, taleple, belirli bir zaman dilimi içerisinde, belirli fiyat karşlığında insanların satın alabileceği ürün miktarı kastedilmektedir (Parasız, 2010: 24).

Talebe dayalı fiyatlandırma kararlarında, firma ürün için doğru fiyatı bulmaya çalışırken, fiyatın talepten nasıl etkilendiğini anlamaya çalışmaktadır (Kimes, Phillips ve Summa, 2012: 110).

\subsection{Rekabete Göre Fiyatlandırma}

Maliyete ve talebe dayalı fiyatlandırma mevcut pazar şartlarındaki rekabeti göz önüne almadığından dolayı rakiplerin olası tepkilerini inmal etmektedirler. Bu da firmaların fiyatlandırma stratejilerini eksik veya yanlış değerlendirmelerine neden olmakta ve müşteri kaybına sebep olmaktadır (i̇slamoğlu, 2013: 422). Rekabet temelli fiyatlandırmada firmalar fiyatlandırma stratejilerini rakiplerinin stratejilerine, maliyetlerine, fiyatlarına ve piyasaya sunduğu tekliflere göre değerlendirirler (Kotler ve Armstrong, 2012: 299).

Fiyatlandırma kararını verecek olan yöneticiler, fiyatlarda yaptıkları herhangi bir değişikliğin rakiplerini nasıl etkileyeceğini düşünmeli ve kendilerine "Rakip ben olsaydım ne yapardım?" sorusunu sormalı ve aldıkları fiyatlandırma kararının sektörün kârlılı̆ı üzerindeki etkilerini ihmal etmemelidirler (Dolan, 2011: 27).

\subsection{Değer Temelli Fiyatlandırma}

Değer temelli fiyatlandırmada müşterinin satın almak istediği ürünle ilgili zihninde belirli bir fiyat vardır. Satıcı müşterinin zihnindeki bu fiyata göre fiyatlandırmayı yapması değer temelli fiyatlandırma olarak adlandırımaktadır (Phillips, 2011: 47). Bu fiyatlandırma yaklaşımında, aslında, müşteri bir ürünü satın alırken belirli bir fiyat karşı̆ı̆ında fayda sağlayacağı değeri satın almaktadır. En nihayetinde satııının sunduğu fiyatın doğru olup olmadığını müşteri belirleyecektir (Kotler ve Armstrong, 2012: 291).

\section{LITERATÜR TARAMASI}

Biçici (2008) tarafından yapılan çalışmada yabancı turistlere 298 anket uygulanmıştır. Çalışmada ele alınan değişkenlerin 9 kalanlı fiyat stratejisi ile ucuzluk arasındaki bağıntı, 9 kalanlı fiyat stratejisi iyi değer algılaması arasındaki ilişki ve yuvarlama fiyat ile kalite arasındaki bağlantı incelenmiştir. Çalışmada korelasyon analizi, $t$ 
testi uygulanmıştır. Çalışmanın sonucunda yuvarlama fiyatın kalanlıya göre daha dürüst algılandığı ve 9 kalanlı fiyat stratejisinin ucuz ama yuvarlamaya fiyata göre daha az kaliteli algılandığı görülmüştür.

Kachaganova (2002) tarafından yapılan çalışmada 44 firmanın üst düzey yöneticilerine anket uygulaması yapılmıştır. Ele alınan değişkenler firmaların fiyatlandırma yöntemleri, fiyat farklılaşması ve rakiplere göre fiyatın nasıl değiştiği incelenmiştir. Çalışmada yüzde analizi kullanılmıştır. Çalışmanın sonucuna göre fiyatlandırma yöntemi olarak en çok maliyete göre fiyatlandırma yapılmaktadır. Firmaların uluslararası pazarlarda fiyat farklılaşması yaptığı ve rakip firmalarla fiyatın aynı olduğu görülmektedir.

Hamidli (2006) tarafından yapılan çalışmada Ankara'da bir yurttaki 108 öğrenciye anket uygulanmıştır. Çalışmada ürünlerin tamamlayıcı olup olmaması ve ürün demeti fiyatının farklı şekillerde sunumu değişkenleri incelenmiştir. Çalışmada tek değişkenli varyans ve ANOVA uygulanmıştır. Çalışmanın sonucuna göre tamamlayıcı ürünlerden oluşmuş olan ürün demetinin satın alma niyeti tamamlayıcı olmayanlara göre daha yüksek olduğu ve ürün demetinin fiyatının farklı şekillerde sunumunun tüketici satın alımını etkilediği ortaya çıkmıştır.

Kırveli (2006) tarafından yapılan çalışmada toplam 4 sektörden (elektronik, giyim, kitap, oyuncak) 200 firmaya anket uygulanmıştır. Çalışmada belgeli ve belgesiz satış yapan firmalar arasındaki fiyat farklılığı ve fiyat dalgalanmaları incelenmiştir. Çalışmada t testi kullanılmıştır. Araştırmanın sonucuna göre belgeli ve belgesiz satış yapanlar arasındaki fiyat farklııklar anlamlı bulunmuştur. Elektronik ürün satıcı firmaların fiyatlarındaki dalgalanmanın diğer sektörlere göre daha fazla olduğu görülmüştür.

Selanik (2004) tarafından yapılan çalışmada demir çelik endüstrisinde 12 firma üzerinde anket çalışması yapılmıştır. Çalışmada fiyatlandırma amaçları, fiyatlandırma yöntemleri ve fiyatlandırmayı etkileyen faktörler incelenmiştir. Çalışmada yüzde analizi kullanılmıştır. Çalışmanın sonucunda fiyatlandırmada amacın kâr olduğu görülmüştür. Fiyatlandırma yönteminin rekabete sonra maliyete daha sonra ise talebe göre olduğu görülmektedir.

Erdoğan (2008) tarafından yapılan çalışmada 1290 işletme ve iktisat öğrencisine anket uygulaması yapılmıştır. Çalışmada Aylık GSM harcama toplamı, tarife sonrası aylık toplam GSM harcaması, firmaların üçüncü derece fiyat farklılaşması uygulayıp uygulamadığı incelenmiştir. Çalışmada korelasyon analizi ve t testi uygulanmıştır. Çalışmanın sonucuna göre öğrencilerin yarısından fazlasının tarife seçiminde birincil öncelik olarak fiyata baktıkları görülmüştür. Ayrıca GSM operatörlerinin üçüncü derece fiyat farklılaşması yapmasıyla öğrencilerin öğrenim durumu ve cinsiyetleri arasında bir ilişki bulunamamıştır.

Karahan (2014) tarafından yapılan çalışmada 4 ve 5 yıldızlı toplam 30 otel için anket uygulaması gerçekleştirilmiştir. Çalışmada otellerin fiyatlandırma biriminin olup olmadığını tespit edilmeye ve hangi fiyatlandırma stratejisini kullandıkları anlaşılmaya çalışılmıştır. Çalışmada yüzde analizi kullanılmıştır. Çalışmanın sonucuna göre otellerin büyük çoğunluğunda fiyatlandırma stratejisi biriminin varlığı tespit edilmiştir. Ayrıca maliyete göre fiyatlandırmanın en çok tercih edilen fiyatlandırma stratejisi olduğu görülmüştür.

Avlonitis ve Indounos (2005) tarafından yapılan çalışmada 6 sektörden (ulaşım sistemi, sigorta, ilaç sanayi, bilgi teknolojileri, havayolları ve bankalar) 170 firmaya anket uygulaması yapılmıştır. Fiyatlandırma amaçları ve fiyatlandırma politikalarının incelendiği çalışmada fiyatlandırma amacı olarak var olan müşterileri kaybetmemek, onların ihtiyaçlarına cevap vermek ve şirket için iyi bir imaj oluşturmaya çalışmak olduğu görülmüştür. Fiyatlandırma politikaları açısından ise firmaların öncelikli tercihinin liste fiyatları daha sonra ise pazarlıklı fiyatlar olduğu sonucuna ulaşılmıştır. Çalışmada faktör analizi kullanılmıştır.

Drozdenko, Jensen ve Coelho (2011) tarafında yapılan çalışmada 398 ev sahibine online anket uygulaması yapılmıştır. Vergi teşvikleri ve yeşil ürünün fiyatı değişken olarak ele alınmıştır. Çalışmanın sonucuna göre vergi teşvikleri yeşil ürüne olan satın almayı destekliyor. Ev sahipleri yeşil olan Mp3 oynatıcılarda \%9,5 oranında fazla ödemeyi kabul ederken yeşil olan bir otomobile ise \%10,4 oranında fazla ödemeyi kabul ediyorlar. Çalışmada ANOVA kullanılmıştır.

Indounas (2014) tarafından yapılan çalışmada fiyatlandırma konusunda uzman 35 yöneticiyle görüşülmüş, ardından 301 firmayla anket çalışması yürütülmüştür. Ele alınan değişkenler firmanın büyüklüğü, rekabet yoğunluğu, stratejik fiyatlandırma, teknolojik karmaşa, pazar karmaşasıdır. Çalışmanın sonucuna göre firmanın 
büyüklüğünün ve rekabet yoğunluğunun stratejik fiyatlandırma üzerinde bir etkisi bulunamamıştır. Teknolojik karmaşa, pazar karmaşasının stratejik fiyatlandırmayı olumsuz etkilediği çalışmanın sonuçları arasındadır. Çalışmada doğrulayıcı faktör, korelasyon ve regresyon analizleri kullanılmıştır.

Noble ve Gruca (1999) tarafından yapılan bir çalışmada 270 firma üzerinde anket çalışması yapılmıştır. Çalışmada maliyet artı fiyatlandırma stratejisi yeni ürün için fiyatlandırma ve değer temelli fiyatlandırma incelenmiştir. Çalışma sonucuna göre maliyet artı fiyatlandırma stratejisinin en çok kullanılan strateji olduğu ortaya çıkmıştır. Yeni ürün için fiyatlandırmada firma eğer maliyet dezavantajına sahipse pazarın kaymağını alma, eğer maliyet avantajına sahipse pazara nüfuz etme stratejisi uygulamaktadır. Değer temelli fiyatlandırma pazarın daraldığı ve fiyat değişikliklerini tespitin zor olduğu pazar dilimlerinde yapılmaktadır. Çalışmada t testi kullanılmıştır.

Obadia (2013) tarafından yapılan çalışmada 278 firma üzerinde anket çalışması yapılmıştır. Çalışmada rekabet yoğunluğu ve bilgi asimetrisi değişken olarak incelenmiştir. Çalışmanın sonucuna göre yüksek rekabet ortamında firmalar fiyat indirimlerine gidiyor ve uygun kredi imkânları sağlıyorlar. Çalışmanın diğer bir sonucu ise yüksek bir bilgi asimetrisi olduğunda firmanın sağlamış olduğu miktar indirimleri firmanın performansına zarar verebilmektedir. Çalışmada en küçük kareler yöntemi, post hoc analizi ve diskriminant geçerliliği kullanılmıştır.

Raymond, Jr ve Kim (2001) tarafından yapılan çalışmada Amerika'dan 95 Kore'den 74 pazarlama yöneticisine anket uygulanmıştır. İncelenen değişkenler yurtiçi fiyatların ve ihracat fiyatının karşılaştırması ile ihracat fiyatı ve yurtiçi fiyatın karmaşıklığıdır. Çalışmanın sonuçlarına göre ihracat fiyatı Amerika'da yurtiçi fiyatlara göre daha yüksek iken, Kore'de ihracat fiyatları yurtiçine göre daha düşüktür. Amerikan ve Kore pazarında yurtiçi ve yurtdışı satışlarda fiyat karmaşıklığı anlamında bir fark bulunamamıştır. Çalışmada faktör analizi, regresyon ve ki kare analizi kullanılmıştır.

Stottinger (2001) tarafından yapılan çalışmada 5 farklı sektörden (sistem, elektrik ve makine mühendisliği, plastik ve mobilya) 45 yöneticiyle derinlemesine mülakat yapılmıştır. Ele alınan değişkenler firmanın ihracattaki deneyimi ve firmanın personel sayısı olarak büyüklüğüdür. Çalışmanın sonuçlarına göre yurtdışı pazarlarda deneyimsiz firmalar katı maliyet artı yöntemini kullanmaktadırlar. Deneyimli firmalar ise kâr maksimizasyonu gibi finansal amaçları kovalıyorlar. Firma ne kadar büyükse fiyatlandırması o kadar merkeziyetçi hale gelmektedir.

Tablo 1: Literatür Taraması

\begin{tabular}{|c|c|c|c|c|}
\hline & $\begin{array}{c}\text { Yazar ve Yayın } \\
\text { Yılı }\end{array}$ & Veri Toplama Yöntemi & $\begin{array}{c}\text { Değişkenler } \\
\text { Uygulanan Analizler }\end{array}$ & Temel Bulgular \\
\hline 1 & Biçici, 2008 & $\begin{array}{l}298 \text { anket uygulandı. Yabancı } \\
\text { turistlere uygulandı. }\end{array}$ & $\begin{array}{c}9 \text { kalanlı fiyat stratejisi } \\
\text { Ucuzluk algısı } \\
9 \text { kalanlı fiyat stratejisi } \\
\text { iyi değer algılaması, } \\
\text { Yuvarlama fiyat yüksek } \\
\text { kalite. } \\
\text { Aritmetik ortalama, } \\
\text { Korelasyon ve t testi }\end{array}$ & $\begin{array}{l}\text { Yuvarlama fiyat kalanlıya göre daha dürüst } \\
\text { algılanıyor. } \\
\text { Kalanlı fiyat ucuz ama yuvarlama fiyat daha } \\
\text { kaliteli algılanıyor. }\end{array}$ \\
\hline 2 & $\begin{array}{l}\text { Kachaganova } \\
2002\end{array}$ & $\begin{array}{c}\text { Anket } 44 \text { kişi firmaların üst düzey } \\
\text { yöneticilerine }\end{array}$ & $\begin{array}{l}\text { Fiyat farklılaşması, } \\
\text { Kullanılan fiyatlandırma } \\
\text { yöntemi } \\
\text { Rakiplere göre ürünün } \\
\text { fiyatı } \\
\text { Yüzde analizi }\end{array}$ & $\begin{array}{l}\text { Büyük çoğunluk fiyat farklılaşması } \\
\text { yapmaktadır. } \\
\begin{array}{l}\text { En çok maliyete göre fiyatlandırma } \\
\text { kullanılmaktadır. }\end{array} \\
\text { Rakiplerle ürün fiyatının aynı olduğu } \\
\text { görülmektedir. }\end{array}$ \\
\hline 3 & Hamidli, 2006 & $\begin{array}{c}108 \text { kişiye uygulandı. Ankara'da bir } \\
\text { yurttaki öğrenciler }\end{array}$ & $\begin{array}{l}\text { Ürünlerin tamamlayıcı } \\
\text { olup olmaması } \\
\text { Ürün demeti fiyatının } \\
\text { farklı şekillerde sunumu }\end{array}$ & $\begin{array}{c}\text { Tamamlayıcı ürünlerden oluşmuş olan ürün } \\
\text { demetinin satın alma niyeti tamamlayıcı } \\
\text { olmayanlara göre daha yüksektir. } \\
\text { Ürün demetinin fiyatının farklı şekillerde } \\
\text { sunumu tüketici satın alımını }\end{array}$ \\
\hline
\end{tabular}




\begin{tabular}{|c|c|c|c|c|}
\hline & & & $\begin{array}{c}\text { Tek değisskenli Varyans } \\
\text { ANOVA }\end{array}$ & etkilemektedir. \\
\hline 4 & Kırveli, 2006 & $\begin{array}{c}200 \text { firmaya anket uygulandı. } 4 \text { ayrı } \\
\text { (elektronik, giyim, kitap, oyuncak) } \\
\text { Belgeli satış yapan firmalar ile } \\
\text { belgesiz satıs yapan firmalar } \\
\text { incelendi. }\end{array}$ & $\begin{array}{c}\text { Belgeli ve belgesiz satış } \\
\text { yapanlar arasındaki fiyat } \\
\text { farklılıkları } \\
\text { Fiyat dalgalanması } \\
\text { T Testi }\end{array}$ & $\begin{array}{l}\text { Belgeli ve belgesiz satış yapanlar arasındaki } \\
\text { fiyat farklııılar anlamlı bulunmuştur. } \\
\text { Elektronik ürün satıcı firmaların } \\
\text { fiyatlarındaki dalgalanmanın diğer } \\
\text { sektörlere göre daha fazla olduğu } \\
\text { görülmüştür. }\end{array}$ \\
\hline 5 & Selanik, 2004 & Anket 12 demir çelik işletmesi & $\begin{array}{l}\text { Fiyatlandırma Amaçları } \\
\text { Fiyatlandırmayı } \\
\text { Etkileyen Faktörler, } \\
\text { Maliyete Talebe } \\
\text { Rekabete } \\
\text { Coğrafi Fiyat } \\
\text { Yüzde Analizi }\end{array}$ & $\begin{array}{l}\text { Fiyatlandırma amacın öncelikli olarak kar } \\
\text { olduğu görülmüştür. } \\
\text { Fiyatlandırma yönteminin rekabete sonra } \\
\text { maliyete daha sonra ise talebe göre olduğu } \\
\text { görülmektedir. }\end{array}$ \\
\hline 6 & Erdoğan, 2008 & $\begin{array}{l}1290 \text { öğrenciye anket uygulaması. } \\
\text { Anadolu, Osmangazi, Bilecik ve } \\
\text { Dumlupınar üniversitelerindeki } \\
\text { işletme ve iktisat öğrencileri }\end{array}$ & $\begin{array}{c}\text { Aylık GSM harcama } \\
\text { toplamı } \\
\text { Tarife üyeliği } \\
\text { Tarife sonrası aylık } \\
\text { toplam GSM harcaması } \\
\text { Firmaların üçüncü } \\
\text { derece fiyat farklılaşması } \\
\text { uygulaması } \\
\text { T testi } \\
\text { Korelasyon }\end{array}$ & $\begin{array}{l}\text { Tarife seçiminde öğrencilerin 647'si dakika } \\
\text { başına düşen fiyatların düşük olmasını } \\
\text { birincil olarak tercih etmiştir. } \\
\text { Üçüncü dereceden fiyat farklılaşmasında } \\
\text { öğrencilerin bay ve bayan olması arasında } \\
\text { herhangi bir fark yoktur. }\end{array}$ \\
\hline 7 & Karahan, 2014 & $\begin{array}{c}30 \text { anket Güneydoğu Anadolu } \\
\text { Bölgesindeki } 4 \text { ve } 5 \text { yııdızlı otellere } \\
\text { yapılmıştır. }\end{array}$ & $\begin{array}{l}\text { Otellerin Fiyatlandırma } \\
\text { Stratejileri Birimi } \\
\text { Sahipliği } \\
\text { Değer Tabanlı } \\
\text { Fiyatlandırmanın } \\
\text { Dikkate Alınma Sıklığı } \\
\text { Yüzde Analizi }\end{array}$ & $\begin{array}{l}\text { Otellerden } 23 \text { 'ünün (\% 77) fiyatlandırma } \\
\text { birimine sahip olduğu görülmüştür. } \\
\text { Otellerin fiyatlandırma stratejisi olarak } \\
\text { maliyet tabanlı fiyatlandırma stratejisini } \\
\text { çoğunlukla kullandıkları tespit edilmiştir. }\end{array}$ \\
\hline 8 & $\begin{array}{c}\text { Avlonitis ve } \\
\text { Indounos, } 2005\end{array}$ & $\begin{array}{l}\text { Yunanistan'da } 170 \text { şirkete anket } \\
\text { uygulandı. } 6 \text { sektör seçildi. Ulaşım } \\
\text { sistemi, sigorta, ilaç sanayi, bilgi } \\
\text { teknolojileri, havayolları ve bankalar }\end{array}$ & $\begin{array}{l}\text { Fiyatlandırma amaçları } \\
\text { Fiyatlandırma } \\
\text { politikaları } \\
\text { Yüzde Analizi } \\
\text { Faktör analizi }\end{array}$ & $\begin{array}{l}\text { Firmaların en önemli fiyatlandırma amaçları } \\
\text { var olan müşterileri kaybetmemek, onların } \\
\text { ihtiyaçlarına cevap vermek ve şirket için iyi } \\
\text { bir imaj oluşturmaya çalışmaktır. } \\
\text { Fiyatlandırma politikaları açııından } \\
\text { firmaların öncelikli tercihi liste fiyatları daha } \\
\text { sonra ise pazarlıklı fiyatlarıdır }\end{array}$ \\
\hline 9 & $\begin{array}{l}\text { Drozdenko, } \\
\text { Jensen, Coelho } \\
2011\end{array}$ & Online anket 398 ev sahibi. & $\begin{array}{l}\text { Vergi teşvikleri } \\
\text { Yeşil ürün fiyatı } \\
\text { Anova }\end{array}$ & $\begin{array}{l}\text { Vergi teşvikleri yeşil ürüne olan satın almayı } \\
\text { destekliyor. } \\
\text { Ev sahipleri yeşil olan Mp3 oynatıcılarda } \\
\% 9,5 \text { oranında fazla ödemeyi kabul ederken } \\
\text { yeşil olan bir otomobile ise } \% 10,4 \text { oranında } \\
\text { fazla ödemeyi kabul ediyorlar. }\end{array}$ \\
\hline
\end{tabular}




\begin{tabular}{|c|c|c|c|c|}
\hline 10 & Indounas, 2014 & $\begin{array}{l}\text { Açık uçlu sorular } 301 \text { firma seçildi. } 7 \\
\text { farklı hizmet sektöründen seçildi. } \\
\text { Ayrıca } 35 \text { yöneticiyle görüşme }\end{array}$ & $\begin{array}{l}\text { Firmanın büyüklüğü } \\
\text { Rekabet yoğunluğu } \\
\text { Stratejik fiyatlandırma } \\
\text { Teknolojik karmaşa } \\
\text { Pazar karmaşası } \\
\text { Doğrulayıcı faktör } \\
\text { analizi } \\
\text { Korelasyon analizi } \\
\text { Regresyon analizi } \\
\text { T testi }\end{array}$ & $\begin{array}{l}\text { Firmanın büyüklüğünün stratejik } \\
\text { fiyatlandırma üzerinde bir etkisi } \\
\text { bulunamamıştır. } \\
\text { Rekabet yoğunluğunun stratejik } \\
\text { fiyatlandırmada bir etkisi bulunamamıştır. } \\
\text { Teknolojik karmaşa, pazar karmaşası } \\
\text { stratejik fiyatlandırmayı olumsuz etkiliyor. }\end{array}$ \\
\hline 11 & $\begin{array}{c}\text { Noble ve Gruca } \\
1999\end{array}$ & $\begin{array}{l}\text { Dayanıklı tüketim malları sektöründe } \\
\text { anket uygulaması yapılmıştır. } 270 \\
\text { firma cevaplamıştır. }\end{array}$ & $\begin{array}{l}\text { Maliyet artı } \\
\text { fiyatlandırma } \\
\text { Yeni ürün için } \\
\text { fiyatlandırma } \\
\text { Değer temelli } \\
\text { fiyatlandırma } \\
\text { T testi }\end{array}$ & $\begin{array}{l}\text { Maliyet artı fiyatlandırma stratejisinin en } \\
\text { çok kullanılan strateji olduğu ortaya } \\
\text { çıkmıştır. } \\
\text { Yeni ürün için fiyatlandırmada firma eğer } \\
\text { maliyet dezavantajına sahipse pazarın } \\
\text { kaymağını alma, eğer maliyet avantajına } \\
\text { sahipse pazara nüfuz etme stratejisi } \\
\text { uygulamaktadır. } \\
\text { Müşteri değerine göre fiyatlandırma } \\
\text { pazarın daraldığı ve fiyat değişikliklerinin } \\
\text { tespitin zor olduğu pazar dilimlerinde } \\
\text { yapıımaktadır. }\end{array}$ \\
\hline 12 & Obadia, 2013 & $\begin{array}{l}5 \text { sektörden } 278 \text { firmaya } \\
\text { anket uygulandı. }\end{array}$ & $\begin{array}{l}\text { Rekabetçi yoğunluk } \\
\text { Bilgi asimetrisi } \\
\text { Parçalı en küçük kareler } \\
\text { yöntemi, } \\
\text { Diskriminant, } \\
\text { Post hoc analizi }\end{array}$ & $\begin{array}{l}\text { Yüksek rekabet ortamında } \\
\text { Firmalar fiyat indirimlerine gidiyor ve uygun } \\
\text { kredi imkânları sağlıyorlar. } \\
\text { Yüksek bir bilgi asimetrisi olduğunda } \\
\text { firmanın sağlamış olduğu miktar indirimleri } \\
\text { firmanın performansına zarar } \\
\text { verebilmektedir. }\end{array}$ \\
\hline 13 & $\begin{array}{l}\text { Raymond, Jr, } \\
\text { Kim } 2001\end{array}$ & $\begin{array}{c}\text { Amerika'dan } 95 \text { pazarlama } \\
\text { yöneticisine, Kore'den } 74 \text { pazarlama } \\
\text { yöneticisi anket uygulandı. }\end{array}$ & $\begin{array}{l}\text { Yurtiçi fiyatlar ve ihracat } \\
\text { fiyatının karşılaştırması } \\
\text { Ihracat fiyatı ve yurtiçi } \\
\text { fiyatın karmaşıklığı } \\
\text { Faktör analizi } \\
\text { Regresyon analizi } \\
\text { Ki kare }\end{array}$ & $\begin{array}{l}\text { İhracat fiyatı Amerika'da yurtiçi fiyatlara } \\
\text { göre daha yüksek iken, Kore'de ihracat } \\
\text { fiyatları yurtiçine göre daha düşüktür. } \\
\text { Amerikan ve Kore pazarında yurtiçi ve } \\
\text { yurtdışı satışlarda fiyat karmaşıkıı̆ı } \\
\text { anlamında bir fark bulunamamıştır. }\end{array}$ \\
\hline 14 & Stottinger, 2001 & $\begin{array}{l}5 \text { farklı sektörden } 45 \text { yöneticiyle } \\
\text { derinlemesine mülakat yapıldı. }\end{array}$ & $\begin{array}{c}\text { Firmanın ihracattaki } \\
\text { deneyimi } \\
\text { Firmanın personel sayısı } \\
\text { olarak büyüklüğü }\end{array}$ & $\begin{array}{l}\text { Yurtdışı pazarlarda deneyimsiz firmalar katı } \\
\text { maliyet artı yöntemini kullanmaktadırlar. } \\
\text { Deneyimli firmalar ise kâr maksimizasyonu } \\
\text { gibi finansal amaçları kovalıyorlar. } \\
\text { Firma ne kadar büyükse fiyatlandırması o } \\
\text { kadar merkeziyetçi hale gelmektedir. }\end{array}$ \\
\hline 15 & $\begin{array}{c}\text { Theodosiou } \\
\text { Katsikeas, } 2001\end{array}$ & $\begin{array}{l}\text { İngiltere Almanya ve Japonya kökenli } \\
505 \text { firma üzerinde anket uygulaması }\end{array}$ & $\begin{array}{l}\text { Ana ülke ile misafir ülke } \\
\text { arasındaki ekonomik }\end{array}$ & $\begin{array}{l}\text { Ana ülke ile misafir ülke arasındaki } \\
\text { ekonomik çevre benzerliği fiyat }\end{array}$ \\
\hline
\end{tabular}




\begin{tabular}{|c|c|c|c|c|}
\hline & & yapıldı. & $\begin{array}{c}\text { çevre benzerliği } \\
\text { Fiyatın standardizasyonu } \\
\text { Ana ülke ile misafir ülke } \\
\text { arasındaki dağııı } \\
\text { kanalının yapısı } \\
\\
\text { Scatter diagramı } \\
\text { Korelasyon analizi } \\
\text { Çoklu regresyon analizi }\end{array}$ & $\begin{array}{l}\text { standardizasyonu arasında ilişki vardır. } \\
\text { Ana ülke ile misafir ülke arasındaki dağııım } \\
\text { kanalının yapısı fiyat standardizasyonu } \\
\text { arasında ilişki bulunamamışıtır. }\end{array}$ \\
\hline 16 & $\begin{array}{l}\text { Cavuşgil, Chan } \\
\text { ve Zang, } 2002\end{array}$ & $\begin{array}{c}24 \text { yöneticiyle derinlemesine mülakat } \\
\text { yapıldı. Ardından } 404 \text { anket } \\
\text { uygulandı. }\end{array}$ & $\begin{array}{c}\text { Firmanın uluslararası } \\
\text { deneyimi } \\
\text { Maliyet artı } \\
\text { fiyatlandırma } \\
\\
\text { Faktör Analizi } \\
\text { Güvenilirlik analizi } \\
\text { Kümeleme analizi } \\
\text { Anova }\end{array}$ & $\begin{array}{l}\text { Uluslararası deneyimi güçlü firmalar } \\
\text { standart ürünler üreterek maliyet artı } \\
\text { fiyatlandırma uyguluyorlar. } \\
\text { Uluslararası deneyimi zayıf olan firmalar ise } \\
\text { maliyet artı fiyatlandırmadan kaçınmaya } \\
\text { çalışıyorlar. }\end{array}$ \\
\hline 17 & $\begin{array}{c}\text { Myers ve } \\
\text { Harvey, } 2001\end{array}$ & $\begin{array}{l}12 \text { tane uluslararası yöneticiyle } \\
\text { derinlemesine görüşme. } \\
297 \text { firmayla anket uygulaması } \\
\text { yapıldı. }\end{array}$ & $\begin{array}{l}\text { Uluslararası deneyim } \\
\text { Fiyatlandırma } \\
\text { kontrolünün derecesi } \\
\text { Firma büyüklüğü } \\
\text { Kanal Bağımlıı̆̆ı } \\
\\
\text { Regresyon Analizi } \\
\text { T testi } \\
\text { Diskriminant analizi }\end{array}$ & $\begin{array}{l}\text { Firmanın uluslararası deneyimi ne kadar } \\
\text { iyiyse o firmanın fiyatlandırma kontrolü de } \\
\text { o kadar güçlüdür. } \\
\text { Firmanın kanal bağımlı̈ı̆̆ı ne kadar } \\
\text { yüksekse fiyat kontrolünü o ölçüde az } \\
\text { sağlamaktadır. }\end{array}$ \\
\hline 18 & $\begin{array}{l}\text { Tzokas Hart } \\
\text { Argouslidis } \\
\text { Saren } 2000\end{array}$ & $\begin{array}{l}3 \text { farklı sektör seçildi. } \\
178 \text { anket uygulandı. }\end{array}$ & $\begin{array}{l}\text { Fiyatlandırma kararı } \\
\text { Fiyatlandırma yöntemi } \\
\text { Faktör analizi } \\
\text { T testi }\end{array}$ & $\begin{array}{l}\text { Firmaların fiyatlandırma kararlarında en } \\
\text { önemli etken ürün maliyetleridir. } \\
\text { En çok kullanılan fiyatlandırma yöntemi } \\
\text { maliyete göre fiyatlandırmadır. }\end{array}$ \\
\hline
\end{tabular}

Theodosiou ve Katsikeas (2001) tarafından yapılan çalıșmada İngiltere Almanya ve Japonya kökenli 505 firma üzerinde anket uygulaması yapılmıştır. Çalışmada ana ülke ile misafir ülke arasındaki ekonomik çevre benzerliği, fiyatın standardizasyonu ve ana ülke ile misafir ülke arasındaki dağııım kanalı gibi değişkenler incelenmiştir. Çalışmanın sonuçlarına göre ana ülke ile misafir ülke arasındaki ekonomik çevre benzerliği fiyat standardizasyonu arasında ilişki vardır. Ana ülke ile misafir ülke arasındaki dağıtım kanalının yapısı fiyat standardizasyonu arasında ilişki bulunamamıştır. Çalışmada korelasyon ve çoklu regresyon analizleri kullanılmıştır.

Cavuşgil, Chan ve Zang (2002) tarafından yapılan çalışmada ilk önce 24 uluslararası firma yöneticisiyle görüşülmüş, ardından 404 firmaya anket uygulanmıştır. Uluslararası deneyim ve fiyatlandırma kararları değişken olarak incelenmiştir. Çalışmanın sonuçlarına göre uluslararası deneyimi güçlü firmalar standart ürünler üreterek maliyet artı fiyatlandırma uyguluyorlar. Uluslararası deneyimi zayıf olan firmalar ise maliyet artı fiyatlandırmadan kaçınmaya çalışıyorlar. Çalışmada faktör analizi, kümeleme analizi ve ANOVA kullanılımıştır.

Myers ve Harvey (2001) tarafından yapılan çalışmada öncesinde 12 tane uluslararası yöneticiyle derinlemesine mülakat yapılmış ardından 297 firmaya anket uygulanmıştır. İncelenen değişkenler firmanın uluslararası deneyimi, fiyatlandırma kontrolünün derecesi, firmanın büyüklüğü ve kanal bağımlılı̆̆ıdır. Çalışmanın sonuçlarına göre firmanın uluslararası deneyimi ne kadar iyiyse o firmanın fiyatlandırma kontrolü de o kadar 
güçlüdür. Firma büyüklüğü ve fiyatlandırma kontrolü arasında anlamlı bir ilişki vardır. Ayrıca firmanın kanal bağımlılığı ne kadar yüksekse fiyat kontrolünü o ölçüde az sağlamaktadır. Çalışmada regresyon ve diskriminant analizi kullanılmıştır.

Tzokas vd. (2000) tarafından yapılan çalışmada 3 farklı sektörden (kimya, metal ve plastik) 178 firmaya anket uygulanmıştır. Ele alınan değişkenler fiyatlandırma kararı ve yöntemidir. Elde edilen sonuçlarına göre fiyatlandırma kararlarında en önemli etken ürün maliyeti iken fiyatlandırma yöntemi olarak en çok maliyet artı fiyatlandırma kullanılmaktadır. Çalışmada faktör analizi ve t testi uygulanmıştır.

\section{SONUC}

Fiyatlandırma günümüzde işletmeler açısından en önemli konuların başında gelmektedir. İşletmeler doğru fiyatlandırma politikaları neticesinde devamlıı̆ını sağlamakta, belirli oranlarda kâr elde etmekte ve pazar payını artırmaya çalışmaktadır. Bu sebeple fiyatlandırma konusunun işletmenin amaçları gerçekleştirmede kritik bir role sahip olduğu söylenebilir. İşletmeler açısından fiyatlandırmanın önemi bu amaçlarla da sınırlı kalmamaktadır. Fiyatlandırma ayrıca işletmenin rakipleriyle rekabet edebilmesinde, markalaşmasında ve ürünün gerçek değerini yansıtması açısından da önemli bir rol üstlenmektedir.

Fiyatlandırma müşterilerin ürün veya hizmeti satın almasında etkili olmaktadır. İşletmelerin fiyatlandırma kararlarında ne fiyatları düşük tutarak ürün veya hizmetin değerini azaltmaları ne de yüksek fiyatlar belirleyerek müşteri kaybına sebep olabilecek bir faaliyette bulunmamaları gerekmektedir.

Çalışma kapsamında fiyatlandırmayla ilgili bir literatür taraması yapılmıştır. Literatür taraması incelendiğinde yapılan çalışmaların çoğunda anket uygulanmış olduğu görülmektedir. Bununla beraber literatürde nitel çalışma yapıldıktan sonra anket uygulaması yapıldığı gibi sadece nitel olarak gerçekleştirilen çalışmaların bulunduğu da gözlemlenmektedir.

Yapılan anket uygulamalarının sayısı ve uygulandığı kesime göre çalışmalarda farklılıklar olduğu gözlemlenmektedir. Öğrencilerle, yabancı turistlerle ve ev sahipleriyle yapılan çalışmalarda uygulanan anket sayısı 108 ile 1290 arasında değişirken firma yöneticilerine uygulanan anketlerde bu sayı 12 ile 505 firma arasında değişkenlik gösterebilmektedir. Sadece derinlemesine görüşme yapılan bir nitel çalışmada 45 firma yöneticisiyle görüşme gerçekleştirilmiştir. Fakat öncesinde nitel daha sonrasında firma yöneticileriyle anket uygulaması yapılan çalışmalarda nitel görüşme sayısının 12 ile 35 arasında olduğu gözlemlenmektedir. Bu çalışmalarda daha sonra uygulanan anket sayısı ise 170 ile 404 arasında değişmektedir. Gerek nitel gerekse anket veya öncesinde nitel daha sonra anket uygulaması yapılan çalışmalarda görüşmelerin çoğunun firma yöneticileriyle yapıldığı görülmektedir.

Yapılan çalışmalarda uygulanan analizlerin çoğunlukla t testi, regresyon, korelasyon, faktör, ki-kare, diskriminant analizleriyle ve ANOVA olduğu görülmektedir. Nitel gerçekleştirilen çalışmada yapılan görüşmelerin analizi iki bağımsız araştırmacı eşliğinde değerlendirilerek gerçekleştirilmiştir.

Ele alınan değişkenler açısından incelendiğinde, çalışmalarda genellikle fiyatlandırmanın amaçları, fiyatlandırmayı etkileyen faktörler, fiyatlandırma stratejilerinden maliyete göre fiyatlandırma, talebe göre fiyatlandırma ve rekabete göre fiyatlandırma, coğrafi fiyatlandırma, lider fiyatlandırma stratejisinin incelendiği görülmektedir. Fiyatlandırma amaçları olarak en çok karlıı̆ı̆n gözetildiği, fiyatlandırma stratejisi olarak da en çok maliyete dayalı fiyatlandırma stratejisinin kullanıldığı görülmektedir.

Yapılan literatür çalışmaları analiz edildiğinde sektörler bazında yapılmış olan fiyatlandırma çalışmalarının eksikliği göze çarpmaktadır. Gelecek çalışmalarda farklı sektörlerle ilgili fiyatlandırma çalışmaların yapılmasının fiyatlandırmanın daha iyi anlaşımasına yardımcı olacağı düşünülmektedir.

\section{KAYNAKÇA}

Avlonitis, G. J. ve Indounas, K. A. (2005) Pricing Of Services: An Empirical Analysis From The Greek Service Sectors, Journal of Marketing Management, 21(3-4), 339-362. 
Biçici, F. (2008) Yiyecek İ̧ecek Iş̧letmelerinde Yabancı Turistlerin Psikolojik Fiyatlandırma Uygulamalarıla ilgili Algılamaları: Britanyalı Turistler Üzerinde Bir Çalışma, Aydın: Yayımlanmamış Yüksek Lisans Tezi.

Cavusgil, S. T., Chan, K., ve Zhang, C. (2003) Strategic Orientations in Export Pricing: A Clustering Approach To Create Firm Taxonomies, Journal of International Marketing, 11(1), 47-72.

Dolan, R. J. (2011) "Fiyatın Doğru Olduğunu Nasıl Anlarsınız?,". Harvard Business Review Fiyatlandırma, Çev.: I, Gülfidan, İstanbul: Türkiye Metal Sanayicileri Sendikası (s. 11-34).

Drozdenko, R., Jensen, M., ve Coelho, D. (2011) Pricing Of Green Products: Premiums Paid, Consumer Characteristics And Incentives, International Journal of Business, Marketing, and Decision Sciences, 4(1), 106-116.

Erdoğan, M. (2008) Bir Fiyatlama Stratejisi Olarak Üçüncü Dereceden Fiyat Farklılaştırması: Türkiye’de GSM Sektöründe Bir Uygulama, Eskişehir: Yayımlanmamış Yüksek Lisans Tezi.

Hamidli, V. (2006) Ürün Demeti Fiyatlandırmasının Tüketici Satın Almaya Etkisini Ölçmeye Yönelik Bir Uygulama, Ankara: Yayımlanmamış Yüksek Lisans Tezi

Hundekar, S.G. ve Reddy, P.N. ve Appannaiah, H.R. ve Ramanath, H.R. (2010) Principles of Marketing, Mumbai: Himalaya Publishing House. Indounas, K. (2014) The Antecedents Of Strategic Pricing And Its Effect On Company Performance In The Case Of industrial Service Firms, Journal of Services Marketing, 28(5), 402-413.

İslamoğlu, A.H. (2013) Pazarlama Yönetimi Stratejik Yaklaşım, İstanbul: Beta Basım.

Kachaganova, E. (2002) ihracatta Fiyatlandırma ve Kırgızistan'daki Uygulamalar İstanbul: Yayımlanmamış Yüksek Lisans Tezi.

Karahan, M. (2014) Turizm Sektöründe Fiyatlandırma Stratejilerinin Incelenmesi: Güneydoğu Anadolu Bölgesi Örneği, Antalya: Yayımlanmamış Yüksek Lisans Tezi.

Karunakaran, K. (2008) Marketing Management, Mumbai: Himalaya Publishing House.

Kaya, F. (2013) Dış Ticaret ve Finansmanı, İstanbul: Beta Basım.

Kırveli, M. (2006) Kayıtdışı Elektronik Ticaretin Elektronik Ve/Veya Elektronik Ortamlı Ürün/Hizmet Satıcı Firmaların Fiyatlandırma Politikasına Etkisi Ve Anket Uygulaması, Yayımlanmamış Yüksek Lisans Tezi.

Kimes, S.E., Phillips R., ve Summa L. (2012) Pricing in Restaurants, The Oxford Handbook of Pricing Management, Ed.: Ö. Özer ve R. Phillips, Oxford: Oxford University Press, 106-120.

Kotler, P. ve Armstrong, G. (2012) Principles of Marketing, New Jersey: Pearson Prentice Hall.

Myers, M. B., ve Harvey, M. (2001) The Value Of Pricing Control In Export Channels: A Governance Perspective, Journal of International Marketing, 9(4), 1-29.

Noble, P. M., ve Gruca, T. S. (1999) Industrial Pricing: Theory And Managerial Practice, Marketing Science, 18(3), $435-454$.

Obadia, C. (2013). Competitive Export Pricing: The Influence of the Information Context, Journal of International Marketing, 21(2), 62-78.

Oluç, M. (2006) Temel Pazarlama Kavramları, İstanbul: Beta Yayıncılık.

Parasız, İ. (2010) Iktisadın ABC'si, İstanbul: Ezgi Kitabevi.

Peterson, R. (2007) Principles of Marketing, Delhi: Global Media.

Phillips, R.L. (2011) Fiyatlandırma ve Gelir Optimizasyonu, Çev.: A. Demiriz ve H.N. Demiriz, İstanbul: Scala Yayıncılık.

Raymond, M. A., Tanner Jr, J. F., ve Kim, J. (2001) Cost Complexity Of Pricing Decisions For Exporters In Developing And Emerging Market, Journal of International Marketing, 9(3), 19-40.

Selanik, C. (2004) Ihracat Pazarlamasında Fiyatlandırma Politikaları Ve Türk Demir Çelik Sektörüne Uygulanabilme Imkânı, Ankara: Yayımlanmamıs Yüksek Lisans Tezi.

Sherlekar, S.E. ve Gordon, E. (2010) Marketing Management, Mumbai: Himalaya Publishing House.

Sherlekar, S.E. ve Prasad, K.N. ve Victor, S.J.S. Principles of Marketing, Mumbai: Himalaya Publishing House.

Stottinger, B. (2001) Strategic Export Pricing: A Long And Winding Road, Journal of International Marketing, 9(1), 40-63.

Theodosiou, M., ve Katsikeas, C. S. (2001). Factors Influencing The Degree Of International Pricing Strategy Standardization Of Multinational Corporations Journal of International Marketing, 9(3), 1-18.

Tzokas, N., Hart, S., Argouslidis, P., ve Saren, M. (2000) Industrial Export Pricing Practices In The United Kingdom, Industrial Marketing Management, 29(3), 191-204. 